\title{
2015 Award for Impact on the Teaching and Learning of Mathematics
}

W. JAMES LEWIS has received the 2015 AMS Award for Impact on the Teaching and Learning of Mathematics.

\section{Citation}

Throughout his career, W. James “Jim” Lewis has been a tireless advocate of the idea that mathematics research and education go hand in hand. As department chair at University of NebraskaLincoln for fifteen years, he created an atmosphere of commitment to teaching that established the department as a national model among mathematics departments in research universities where both teaching and research are highly valued, integrated, and rewarded. Jim has taken on numerous national leadership roles that shaped the mathematical education of teachers across the country. Jim served as Chair of the steering committee for The Mathematical Education of Teachers (MET1) and chaired the writing team for its recent update (MET2). These documents lay out guidelines for what pre-college teachers of mathematics should know and make a substantive and compelling case that mathematicians can and must be involved in the process by which future teachers obtain this knowledge. These documents have had a transformational effect on the efforts to mathematically educate teachers.

Jim Lewis has truly made significant contributions of lasting value to mathematics education. He has worked directly with pre-college teachers at both the pre-service and in-service levels; he has created sustainable programs whereby others can continue this work; he has worked at a national level to provide guidance to our profession in this domain. He has also made contributions to mathematics education outside of the mathematical education of teachers, creating a replicable culture in which research and education are integrated and valued, enhancing the first-year mathematics experience for college students, and nurturing the next generation of mathematicians who see

DOI: http://dx.doi.org/10.1090/noti1240 education as an integral part of what they do.

\section{Biographical Sketch}

W. James "Jim" Lewis is the Aaron Douglas Professor of Mathematics and director of the Center for Science, Mathematics, and Computer Education at the University of $\mathrm{Ne}$ braska-Lincoln. He is currently on leave from that position to serve as deputy assistant director for Education and Human Resources at the National Sci-

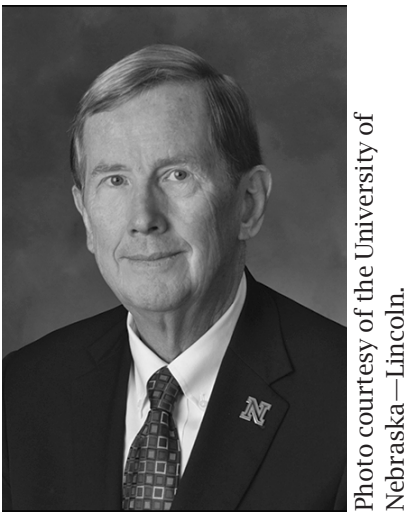

W. James Lewis ence Foundation (NSF).

Lewis's outstanding work has been a significant factor in the several major awards his department has received. Under his leadership as department chair, his department won the Presidential Award for Excellence in Science, Mathematics, and Engineering Mentoring in 1998. That same year, it received the University of Nebraska's University-wide Departmental Teaching Award. And in 2009, it received the AMS Award for an Exemplary Program or Achievement in a Mathematics Department.

Lewis himself has also received many awards. In 2015, he won the Yueh-Gin Gung and Dr. Charles Y. $\mathrm{Hu}$ Award for Distinguished Service to Mathematics, the most prestigious award for service given by the Mathematical Association of America (MAA). His teaching has garnered several awards from his university, and he has been elected to UNL's Academy of Distinguished Teachers. In 2010, he was the Carnegie Foundation's Nebraska Professor of the Year. He has received the UNL Chancellor's Commission on the Status of Women Award for his support of opportunities for women in the mathematical sciences and the university's Louise Pound-George Howard Distinguished Career Award.

Lewis was principal investigator for the Math in the Middle Institute Partnership and NebraskaMATH, two large Math Science Partnerships funded by the NSF that shared the goal of 
educating and supporting Nebraska's K-12 students and teachers.

Lewis has also served on many boards and committees at the national level. He was a member of the Mathematical Sciences Education Board of the National Research Council (NRC) and chair of the Conference Board of the Mathematical Sciences (CBMS). He chaired the steering committee that produced the CBMS report The Mathematical Education of Teachers (2001) and was chair of the writing team that produced the follow-up report The Mathematical Education of Teachers II in 2012. He served as co-chair of the NRC committee that produced Educating Teachers of Science, Mathematics, and Technology: New Practices for the New Millennium (2000). He was a member of the AMS Task Force that produced Towards Excellence: Leading a Doctoral Mathematics Department in the 21st Century (1999). He was chair of the MAA's Coordinating Council on Education, of the AMS Task Force on the First-Year College Mathematics Experience, and of the AMS Committee on Science Policy. In addition, he was a member of the AMS Committee on Education.

Jim Lewis received his $\mathrm{PhD}$ in mathematics from Louisiana State University in 1971.

\section{Response from Jim Lewis}

It is quite an honor to receive this award. It is even more special because Ken Gross is both a friend and a mentor. Indeed, his advice contributed significantly to what we have been able to do here in Nebraska with respect to the mathematical education of teachers.

\section{About the Award}

The Award for Impact on the Teaching and Learning of Mathematics was established by the AMS Committee on Education (COE) in 2013. The award is given annually to a mathematician (or group of mathematicians) who has made significant contributions of lasting value to mathematics education. Priorities of the award include recognition of (a) accomplished mathematicians who have worked directly with pre-college teachers to enhance teachers' impact on mathematics achievement for all students, or (b) sustainable and replicable contributions by mathematicians to improving the mathematics education of students in the first two years of college. The award carries a cash prize of US $\$ 1,000$. The endowment fund that supports the award was established in 2012 by a contribution from Kenneth I. and Mary Lou Gross in honor of their daughters Laura and Karen. The award is presented by the COE acting on the recommendation of a selection subcommittee. The members of the subcommittee for the 2015 award were Arthur Benjamin (chair), Benjamin Braun, Kay Somers, and Jennifer Taback.

The inaugural recipient of the Impact Award was Paul J. Sally, Jr. (2014).

\section{About the Cover}

\section{Illustrating String Theory?}

The cover image was very weakly suggested by the interview with Ed Witten appearing in this issue. Very, very weakly. Mr. G. returns a great many hits to the search string

$$
\text { string theory pictures }
$$

but the visually interesting ones seem to be science fiction, and the ones actually relevant to the topic are visually rather dull line diagrams. We thought of Zen (appropriate, considering that the site of the interview was Kyoto), and in this respect liked the pair

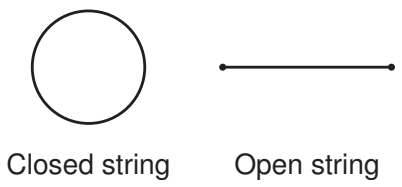

Concentrating on essentials, as it were.

That a great many expositions of string theory reproduce simple variations of these shows that others have faced the same problem we did. Picturing complex objects in 2D that exist in dimensions much higher, whose essential nature involves randomness, is conceivably an impossible task.

Instead, however, we went for something stringy and random, colorful if not mathematically relevant. Fiction rather than fact.

- Bill Casselman
Graphics Editor
notices-covers@ams.org

